\title{
Effects of nutrition optimization strategy on rhamnolipid production in a Pseudomonas aeruginosa strain DN1 for bioremediation of crude oil
}

Kuang-Yi Ma, Meng-Yan Sun, Wen Dong, Chun-Qiu He, Fu-Lin Chen, Yan-Ling Ma*,

Key Laboratory of Resources Biology and Biotechnology in Western China, Ministry of Education,

College of life science, Northwest University, Xi'an, Shaanxi 710069, China

Corresponding author:

Associate Professor Yan-Ling Ma

College of Life Science

Northwest University

710069 Xi'an

CHINA

Tel: +86-13572806395

mayanling@nwu.edu.cn

Fax: +86-2988302411 


\section{Abstract}

An indigenous rhamnolipid biosurfactant-producing Pseudomonas aeruginosa strain

DN1 was isolated from petroleum-contaminated soil samples which could use crude oil as the sole carbon and energy source. A high yield of $25.9 \mathrm{~g} / \mathrm{L}$ rhamnolipid mixture was achieved in a shake flask by nutrition optimization strategy based on high throughput screening of strain DN1, supplemented with palm oil and 5.0g/L sodium nitrate at a $\mathrm{C} / \mathrm{N}$ ratio of 20 . These rhamnolipids reduced the surface tension of water from 45.23 to $25.88 \mathrm{mN} / \mathrm{m}$ with a critical micelle concentration of $50 \mathrm{mg} / \mathrm{L}$, and were able to emulsify several hydrocarbons and showed excellent emulsification (100\%). A total number of 6 monorhamnolipid homologues (Rha- $\mathrm{C}_{8}-\mathrm{C}_{8}$; Rha- $\mathrm{C}_{10: 1}-\mathrm{C}_{8}$; Rha- $\mathrm{C}_{12: 2}$; Rha- $\mathrm{C}_{12}$; Rha- $\mathrm{C}_{14}-\mathrm{C}_{16} ;$ Rha- $\left.\mathrm{C}_{16}-\mathrm{C}_{16}\right)$ and 7 dirhamnolipid homologues (Rha-Rha- $\mathrm{C}_{10} ; \quad$ Rha-Rha- $\mathrm{C}_{12} ; \quad$ Rha-Rha- $\mathrm{C}_{14} ; \quad$ Rha-Rha- $\mathrm{C}_{8}-\mathrm{C}_{10} ; \quad$ Rha-Rha- $\mathrm{C}_{10}-\mathrm{C}_{8: 1}$; Rha-Rha- $\mathrm{C}_{10}-\mathrm{C}_{10}$; Rha-Rha- $\mathrm{C}_{10}-\mathrm{C}_{12}$ ) were detected by liquid chromatography/ mass spectrometry analysis allied to electrospray ionization mass spectrometry. In addition, strain DN1 exhibited an enhanced capacity to degrade crude oil (90.52\%) by its rhamnolipids. The results indicated that the use of nutrition optimization strategy will be the most popular process strategy for high rhamnolipids productivity by this strain for in situ bioremediation of crude oil.

Key words: Pseudomonas aeruginosa; rhamnolipids; luxCDABE; ESI-MS; bioremediation; crude oil; 


\section{Introduction}

Despite recent efforts to introduce renewable energy sources to the market, the world still relies heavily on crude oil, a complex mixture of varying molecular weight hydrocarbons and other organic compounds found beneath the earth's surface. It is a dark sticky fluid naturally-occurring in certain rock formations containing variety of polycyclic aromatic hydrocarbons (PAHs), being damaging to human and the environment (Rulkens \& Bruning, 2005; Silva et al., 2009). Chemicals such as surfactants and solvents have been used for removal of different types of petroleum-contaminants from soils (Kanaly \& Harayama, 2010). However, most surfactants used today are only partially or slowly biodegradable, and as such, they contribute to environmental pollution (Henkel et al., 2012). Those risks have directed attention towards finding environmental-friendly but economically-feasible alternatives (Deepika et al., 2016; Parel et al., 2015). Therefore, in situ stimulation of indigenous microbial populations is often beneficial since they can use injected nutrients or crude oil for their metabolic substrates and produce non-toxic chemicals such as biosurfactants to increase the oil sweep efficiency by changing physiochemical characteristics of reservoirs (Gudina et al., 2012). The available literature indicates that application of biosurfactants hold much promise for oil recovery operations as well as for oil spill bioremediation (Mao et al., 2015).

Biosurfactants are surface-active compounds mainly generated in the vital movement of bacteria, fungi and yeast, which can reduce the surface tension of water/oil and wettability alteration (Bordoloi \& Konwar, 2008). One group among 
these promising biosurfactants are rhamnolipids mainly known from Pseudomonas aeruginosa, which is always considered to be ubiquitous hydrocarbon-degrader and has been shown prominent ability of degrading various hydrocarbons, and could be isolated from diverse environments (Henkel et al., 2012; Geys et al., 2014). Rhamnolipids produced by $P$. aeruginosa that represent one of the most popular classes of microbial biosurfactants and show the highest potential for useful activity with less environmental risk, have demonstrated the capacity to reduction surface tension to around 28-27 mN/m (Reis et al., 2011; Müller et al., 2011). However, for the next generation development of rhamnolipid production processes, considerable obstacles are yet to be surmounted such as relatively high raw-material process and low productivities currently.

To improve rhamnolipid production in P. aeruginosa, a handful of strains have been screened, and fermentation parameters and substrates have been optimized (Müller et al., 2012). Importantly, different $\mathrm{C}$-, $\mathrm{N}$-, and P-sources, together with varying the ratios among nutrients, can influence rhamnolipid production in different $P$. aeruginosa strains (Lan et al., 2015). For example, the use of nitrate (but not ammonium) as the $\mathrm{N}$-source improves rhamnolipid production. Chayabutra and co-workers reported that under P-limitation and denitrifying conditions, P. aeruginosa ATCC $10145\left(28{ }^{\circ} \mathrm{C}, \mathrm{pH} 6.8,2 \%\right.$ (v/v) hexadecane) exhibited an acceptable rate of rhamnolipid production (Chayabutra et al., 2001). Rhamnolipid yields generally range from 3.9-78.56 g/L with different cultivation strategies, although the highest reported yield is $112 \mathrm{~g} / \mathrm{L}$, which was achieved using batch cultivation $\left(30^{\circ} \mathrm{C}, \mathrm{pH} 6.3\right.$, soybean 
oil, N-limitation and $\mathrm{Ca}^{2+}$ free) of P. aeruginosa strains (Giani et al., 1997). However, this finding has not been reproduced due to a lack of sufficient details in the original report (Müller et al., 2011).

The intention of this study was to isolate the indigenous crude oil degrading with rhamnolipid producing bacterial strain from petroleum contaminated soil, and to develop a high throughput screening strategy by enhancing the productivity of rhamnolipids in a shake flask, and to characterize rhamnolipids and demonstrate its potential use as an effective agent for in situ bioremediation of crude oil.

\section{MATERIAL AND METHODS}

\subsection{Chemicals and soils sample collection}

Crude oil was from Yanchang oil field production of Xiasiwan $\left(36^{\circ} 27^{\prime} 36^{\prime \prime} \mathrm{N}\right.$, $108^{\circ} 55^{\prime} 12^{\prime \prime}$ E), a terrestrial oil production located in Northern Shaanxi, China for decades. Petroleum hydrocarbons contaminated soils were also collected from Yanchang oil field production of Xiasiwan. The soils were taken from 2 to $10 \mathrm{~cm}$ depth layer and sieved through a $2-\mathrm{mm}$ screen and stored at $5^{\circ} \mathrm{C}$ in the dark until required. All the chemicals used in this study were of analytical reagent grade, and used without further purification.

\subsection{Screening and isolation of the crude oil degrading with biosurfactant} producing bacterial strain

$10 \mathrm{~g}$ of petroleum contaminated soil was added to $90 \mathrm{~mL}$ basal salt medium (M9) including crude oil $(10 \% \mathrm{w} / \mathrm{v})$ and incubated for 10 days in an orbital shaker set at $30^{\circ} \mathrm{C}$ 
and $150 \mathrm{rpm}$, the active inoculum was used for the isolation of crude oil degrading bacteria, following serial dilution method and spreading over the nutrient agar plates. Many bacterial strains were screened on the basis of their growth in the M9 supplemented with crude oil as a sole source of carbon and energy.

After repeating this procedure for 3 times, these strains were inoculated on agar plates at $30^{\circ} \mathrm{C}$ for $48 \mathrm{~h}$, including the Rhamnolipid Biofurfactant-Specific Screening Medium (RBSSM) and then the Biosurfactant Production Liquid Medium (BPLM, $\mathrm{pH}$ 7.4) which was chosen to further confirm and evaluate its surface activity with different combinations of carbon and nitrogen sources (Nie et al., 2010). The yield of rhamnolipids was quantified in triplicate by the colorimetric determination of sugars with anthrone-sulfate method (Abalos et al., 2001). One of the pure cultures, designated as DN1, was selected for in-depth characterization based on its best growth for crude oil as the sole carbon source and highest yield of rhamnolipids production, which was permanently stocked in $20 \%$ glycerol solution at $-70^{\circ} \mathrm{C}$ and temporarily plated and maintained on a Luria-Bertani (LB) agar plate for fresh inoculation of liquid culture.

\subsection{Taxonomic classification of the strain DN1}

The morphological and physiological characteristics of this isolate were analyzed according to Bergrey's Manual of Systemic Bacteriology and API bacterial identification system, and the phylogenetic identification was obtained by amplifying and sequencing 16S rRNA gene (Edinger et al., 1985). The genomic DNA was extracted from $1 \mathrm{ml}$ of isolate cultured (almost $10^{8}$ bacterial cell) in the deionized 6 
water using the bacterial DNA MiniPrepTM extraction kit (MoBio Laboratories, Inc., USA). For amplification of $16 \mathrm{~S}$ rRNA, bacteria-universal primers $27 \mathrm{f}$ and $1492 \mathrm{r}$ were used (Lee et al., 2003). The PCR product generated was sequenced using Applied Biosystems 3130 Genetic Analyser (Foster City, CA, USA). Sequences were analyzed and assembled in DNA Star Homologues and identified by the BLAST program, which was used to search for similar sequences in the GenBank database services provided by the NCBI (http://www.ncbi.nlm.nih.gov/blast). The 16S rRNA gene sequences of the species most closely related to the strain DN1 were retrieved from the database. The related sequences were preliminarily aligned with the default settings of CLUSTAL X, and complete sequence alignments were performed with MEGA 4.0 programs for the phylogenetic analysis and phylogenetic tree (Thompson et al., 1994; Kumar et al., 2008). The 16S rRNA gene sequence of strain DN1 was deposited in GenBank under the accession number KP119458.

\subsection{Plasmid and strain construction}

To enhance its ability to produce rhamnolipids, a nutrition optimization strategy was established to monitor gene expression using a lux-based reporter for strain DN1. For this purpose, the plasmid pMS402 carrying a sensitive promoterless $\operatorname{luxCDABE}$ reporter gene cluster was used to construct promoter- luxCDABE fusion of the $\operatorname{rhlAB}$ operon, which offers the advantages of a simple and rapid test procedure (Liang et al., 2008). The promoter regions of rhlAB were PCR amplified using high-fidelity Pfx DNA polymerase (Invitrogen) with primer pairs as follow: 5'-GAATCGGATCCATG 
$-\mathrm{C}-3^{\prime}$, which were designed according to the nucleotide acid sequences of PAO1 genomic DNA (purchased from American Type Culture Collection). Restriction sites (underlined) were incorporated into the PCR primers. The promoter regions were cloned into the BamHI site or BamHI-XhoI site upstream of the lux genes on pMS402, respectively. The construct was transformed into strain DN1 by electroporation, yielding strain DN1-lux. Using this reporter, gene expression in liquid cultures was measured in terms of light production (in counts per second) in a Victor3 multilabel plate reader (Perkin-Elmer) every $2 \mathrm{~h}$ for $20 \mathrm{~h}$. Readings were taken from cells inoculated into parallel wells on a 96-well black plate with a transparent bottom.

\subsection{Optimization of cultivation medium composition}

The BPLM medium described above was used in the production of rhamnolipid biosurfactant with strain DN1-lux. In this section, several factors were investigated to obtain the optimum culture media, which included carbon sources (glucose, sucrose, glycerol, palm oil, soybean oil, rapeseed oil, diesel oil, groundnut oil, sodium lactate, fluoranthene, hexane, or octane), nitrogen sources (sodium nitrate, urea, and ammonium nitrate), $\mathrm{C} / \mathrm{N}$ ratios $(10: 1,20: 1,40: 1,60: 1,80: 1$ and 100:1, where the optimum nitrogen sources was kept constant at $5.0 \mathrm{~g} / \mathrm{L}$. Each culture described above was performed in triplicate.

\subsection{Extraction and purification of rhamnolipids}

Strain DN1 was grown in BPLM supplemented with palm oil and sodium nitrate as the carbon and nitrogen source, respectively. After shake flask cultivation for 7 d, 200 
$\mathrm{ml}$ of the production culture was harvested by centrifugation at $10000 \mathrm{rpm}$ (Beckman $\mathrm{J} 2-\mathrm{MC}$ ) for $20 \mathrm{~min}$ at $4^{\circ} \mathrm{C}$ to remove the cells. Then the supernatant was acidified to a $\sim \mathrm{pH}$ 2.0-3.0 with $85 \%$ phosphoric acid and subjected to a triple stage liquid-liquid extraction with 0.3 volume of ice-cold 2:1 chloroform and methanol solution each time, the organic phases were then separated and pooled. The solvent was desiccated in a rotary vacuum evaporator to concentrate the crude extract. The crude extract was further purified twice with $\mathrm{CH}_{2} \mathrm{Cl}_{2}$ and dried with a rotary evaporator to obtain the pure rhamnolipids, which were stored at $-20^{\circ} \mathrm{C}$ for further analysis (Chayabutra et al., 2001).

\subsection{Surface tension and emulsification of purified rhamnolipids}

The surface tension of the cell free culture broth collected at different time intervals was determined by JYW-200A automatic interfacial tension meter using the ring methods (Bordoloi \& Konwar et al., 2008). Based on the surface tension measurement, the critical micelle concentration (CMC) was then obtained by plotting the surface tension as a function of the serial concentration of rhamnolipid solutions with SDS as the control, the surface tension at this point was designated as CMC (Sheppard \& Mulligan, 1987). The emulsification activity was assessed by following Cooper and Goldenberg's protocol (Cooper \& Goldenberg, 1987). Briefly, 2ml of hydrocarbon was added to $2 \mathrm{ml}$ of a rhamnolipids solution and vortexed at high speed for $2 \mathrm{~min}$ and left undisturbed for $24 \mathrm{~h} . E_{24}$ was expressed as the percentage of the height of the emulsified layer divided by the total height of the liquid column. All measurements were taken in triplicate to minimize the experimental errors and to generate averaged 
values.

\subsection{Quantitative analysis and structural characterization of rhamnolipids}

The HPLC/ESI-MS analyses were performed according to previously reported method, with minor modification (Schenk et al., 1995). Negative mass spectra were obtained on a Micromass Q-TOF mass spectrometer (Waters) coupled to a Dionex HPLC system with use of a Gemini C18 column $(2 \times 50 \mathrm{~mm}, 10 \mathrm{~nm}, 5 \mu \mathrm{m}$, Phenomenex). The mass spectrometer was operated in the data dependent mode with a range of $\mathrm{m} / \mathrm{z} 350$ to 2000 . The HPLC mobile phases were $\mathrm{A}: \mathrm{H}_{2} \mathrm{O}$ containing $4.9 \%$ acetonitrile and $0.1 \%$ trifluoroacetate acid (TFA), and B: acetonitrile containing $4.9 \%$ $\mathrm{H}_{2} \mathrm{O}$ and $0.1 \%$ TFA. The rhamnolipids were eluted with a gradient, starting at $1 \%$ solvent $\mathrm{B}$ and holding for $3 \mathrm{~min}$, then ramping to $80 \%$ in $27 \mathrm{~min}$, holding for $6 \mathrm{~min}$, backing to $1 \%$ in $2 \mathrm{~min}$ and holding at $1 \%$ for $1 \mathrm{~min}$. The eluents were directly infused into the mass spectrometer through the ESI probe. The spray voltage of the mass spectrometer was $3.30 \mathrm{kV}$ and the cone voltage $35 \mathrm{~V}$. The desolvation temperature was $413 \mathrm{~K}$ and source temperature $353 \mathrm{~K}$. Nitrogen was used as both cone gas and desolvation gas, with a flow rate of $40 \mathrm{~L} / \mathrm{h}$ and $400 \mathrm{~L} / \mathrm{h}$, respectively. The collision energy was set to $10 \mathrm{~V}$. Mass Lynx (ver. 4.0) software was used for analysis and post processing.

\subsection{Testing the ability of strain DN1 to biodegrade crude oil}

Erlenmeyer flasks $(500-\mathrm{mL})$ were filled with $200 \mathrm{~mL}$ of the optimized medium composition of BPLM and crude oil, which was sterilized three times at $121^{\circ} \mathrm{C}$ for 30 
min to final concentrations of $10 \%$ as the sole carbon source. Strain DN1 was inoculated in $200 \mathrm{~mL}$ of the above medium and incubated for $15 \mathrm{~d}$ at $30{ }^{\circ} \mathrm{C}$ with rotation at $200 \mathrm{rpm}$. Control flasks contained the medium with crude oil and autoclaved cells of strain DN1. Triplicate shake flasks were analyzed after every one day of incubation for the concentration of strain DN1. For the analysis of the residual crude oil, the cultures per time were centrifuged and the aqueous phase was extracted with an equal volume of hexane, methylene chloride and chloroform individually in sequence. In each extraction, the mixture was centrifuged for $10 \mathrm{~min}$ at $8000 \mathrm{rpm}$. The centrifuged crude oil and the gel-like solid were combined and taken as residual crude oil. $100 \mathrm{mg}$ of the residual crude oil was dissolved in n-pentane, and the insoluble fraction was filtered and called asphaltene. The n-pentane soluble fraction was concentrated and loaded on the top of a silica gel G (60-120 mesh) column ( $2 \mathrm{~cm}$ $\times 30 \mathrm{~cm})$ and eluted with solvents of different polarities. The alkane fraction was eluted with $100 \mathrm{~mL}$ of hexane, followed by elution of the aromatic hydrocarbon fraction with $100 \mathrm{~mL}$ of toluene, while the fraction of nonhydrocarbon was eluted with $100 \mathrm{~mL}$ of methanol and $100 \mathrm{~mL}$ of chloroform (Nie et al., 2010).

\section{RESULTS AND DISCUSSION}

\subsection{Identification of the strain DN1}

Many bacterial strains were isolated from petroleum-contaminated soil which had the ability to either produce visual rhamnolipids as indicated by the presence of blue halos, or utilize crude oil as a sole source of carbon and energy. Among these isolates, 
one strain code as DN1 was not only capable of highly producing the biosurfactants but, it was also able to degrade crude oil effectively. The nearly complete $16 \mathrm{~S}$ rRNA gene sequence (1475bp) of strain DN1 was obtained and phylogenetic analysis conducted to determine that it belonged to Gamma Proteobacteria, showing the highest $16 \mathrm{~S}$ rRNA gene sequence similarity of $98 \%$ with Pseudomonas aeruginosa (Fig.1). This strain was oval to rod-shaped $(0.5-0.8 \mu \mathrm{m} \times 1.5-3.0 \mu \mathrm{m})$, gram-negative and motile with a single polar flagellum. Colonies $(2 \mathrm{~mm} \sim 3 \mathrm{~mm})$ growing on $\mathrm{LB}$ agar for $24 \mathrm{~h}$ at $37^{\circ} \mathrm{C}$ were rough, circular convex, wet and yellowish-brown in color. The strain was tolerant to a wide variety of physical conditions, including temperature and $\mathrm{pH}$, with the optimum growth occurring at a $\mathrm{pH} 6.5-7.5$ and $30-37^{\circ} \mathrm{C}$. It was positive for citrate, catalase, oxidase, aerobic nitrite reduction, anaerobic nitrate reduction and denitrification, as well as for the hydrolysis of gelatin. According to API-test results, the biochemical profiles seemed to ferment some carbohydrates by the strain. Morphological, physiological and phylogenetic properties indicated that strain DN1 (CCTCC NO: M2011287) was a member of the genus Pseudomonas, and the accession number in the GenBank is KP119458.

\subsection{Optimization of nutrition conditions}

Rhamnolipid production requires appropriate growth conditions. While there is a broad spectrum of substrates which have been employed for the production of rhamnolipids, less expensive substrates will be pursed towards optimization of rhamnolipid production (Müller et al., 2012). Fig.2A shows that DN1-lux was capable of utilizing various substrates as the sole carbon and energy sources, and the yield of 
rhamnolipid was dependent on the carbon source used. Specifically, palm oil led to the highest production of rhamnolipid by DN1-lux, and rapeseed oil was the second most effective substrate. Use of either fluoranthene, hexane or octane as the sole carbon source, lead to a similar level of rhamnolipid expression, but in all these cases, the absolute level was significantly lower than that produced in the presence of palm oil. Their ranking was as follows: palm oil $>$ glycerol $>$ glucose $>$ diesel oil $>$ sucrose $>$ groundnut oil > hexane. Hereby, palm oil was the preferred carbon source of the DN1 strain for rhamnolipid production, which is in agreement with the fact that carbon source preference for rhamnolipid production by microorganisms is strain-dependent (Wu et al., 2008). For example, rapeseed oil has frequently been used as the carbon substrate for rhamnolipid production with $P$. aeruginosa strains (Mata-Sandoval et al., 2001). This gives a higher rhamnolipid yield than does either glucose or glycerol (Wu et al., 2008), although these last two substrates are still more effective than olive oil and soybean in P. aeruginosa.

The best nitrogen source for rhamnolipid production in this study was sodium nitrate, which was followed by ammonium chloride, urea and ammonium nitrate (Fig.2B). This finding agrees with other reports in which sodium nitrate was more effective than ammonium sulphate and urea for rhamnolipid production (Prieto et al., 2008). These results indicate that bacterial metabolism may be inhibited due to a nutrient transport deficiency, since nitrate first undergoes dissimilatory nitrate reduction to ammonium and is then assimilated by glutamine-glutamate metabolism. This is consistent with reports that rhamnolipid production is more efficient under 
nitrogen-limiting conditions (Chayabutra et al., 2001).

The $\mathrm{C} / \mathrm{N}$ ratio is another vital factor that influences the ability of microorganisms to produce rhamnolipids. Using the best carbon and the nitrogen sources (palm oil and $\mathrm{NaNO}_{3}$, respectively), the effect of $\mathrm{C} / \mathrm{N}$ ratio on rhamnolipid production was determined. We revealed that a $\mathrm{C} / \mathrm{N}$ ratio of 20 gave with yielded maximum rhamnolipid expression (Fig. 2C). Thus, this studies indicate that both the type and relative concentrations of carbon and nitrogen substrates dictate the level of rhamnolipid production. This is consistent with the previous findings that the greatest rhamnolipid yield $(5.5 \mathrm{~g} / \mathrm{L})$ was produced using glucose as the carbon source, and a C/N ratio of 22 (Onwosi \& Odibo, 2012). In contrast to study of Onwosi, which found that productivity tended to decrease with $\mathrm{C} / \mathrm{N}$ ratios greater than 50 , we observed higher expression of rhamnolipids at a $\mathrm{C} / \mathrm{N}$ ratio of 90 . This could be attributed to the use of palm oil as the sole carbon source under nitrogen-limiting growth conditions. Such conditions favor rhamnolipid production prior to exhaustion of nitrogen during the transition from growth to stationary phase, as during this period both RpoS and RpoN should be active (Müller et al., 2012). Thus, rhamnolipid production coincides with the onset of the stationary phase under the control of RpoS in response to nutrient limitation (Reis et al., 2011).

\subsection{Growth and rhamnolipids production in shake flask}

Supplemented with the optimization of the cultivation medium composition, the rhamnolipids concentration and strain growth trends during the 7-days in a shake flask 
were presented in Fig.3A. The cells were in exponential phase after 2 day of cultivation. Rhamnolipid synthesis lagged behind cell growth, and the rhamnolipid production still had a growth trend in the final stage, the maximum rhamnolipid yield was $25.9 \mathrm{~g} / \mathrm{L}$ after 7 days, at which point the culture reached the stationary phase of growth. Encouragingly, the rhamnolipid yield was up to $13.8 \mathrm{~g} / \mathrm{L}$ when the strain DN1 grew well in M9 with crude oil as substrate. Although a maximum concentration of $112 \mathrm{~g} / \mathrm{L}$ rhamnolipids has been reported and patented (Giani et al., 1997), this work refers to shake flask experiments with $P$. aeruginosa wild-type strain. Compared to other host strains such as $P$. fluorescens, $P$. putida and $P$. oleovorans with a maximum concentration of $7.2 \mathrm{~g} / \mathrm{L}$ rhamnolipids (Müller et al., 2011), the yield from wide-type strain DN1 was enhanced by the nutrition optimization strategy.

\subsection{Surface activity of rhamnolipids}

CMC indicates the minimum concentration of rhamnolipid necessary for the maximum reduction in surface and interfacial tension. The rhamnolipid mixture extracted by strain DN1 was able to reduce the surface tension of water significantly. The profile of changes in surface tension versus rhamnolipid concentration was presented in Fig. 3B. As seen in Fig.3B, the surface tension of water has been vastly decreased from $45.23 \mathrm{mN} / \mathrm{m}$ to $25.88 \mathrm{mN} / \mathrm{m}$ as rhamnolipid concentration increased to $50 \mathrm{mg} / \mathrm{L}$, and kept nearly unchanged above this concentration, which was excellent than the control. A wide range of CMC values have been reported in the literature. For example, Abalos et al reported $230 \mathrm{mg} / \mathrm{L}$ for a mixture of seven rhamnolipid homologues, and Amani et al reported $120 \mathrm{mg} / \mathrm{L}$ for the rhamnolipid synthesized by $P$. 
aeruginisa MM1011(Abalos et al., 2001; Amani et al., 2013). To sum up, the rhamnolipids obtained from strain DN1 exhibited excellent surface activity with a low CMC, which was much lower than most of other biosurfactants reported so far.

Furthermore, the ability to form and stabilize emulsions is one of the most important features to be considered for the practical application of a surfactant. The emulsification index $(E)$ of the non-purified rhamnolipids was determined at $24 \mathrm{~h}$. After $24 \mathrm{~h}$, cell extracts emulsified hexane and other hydrocarbons used for the tests completely ( $E_{24}=100 \%$ ), which were stable to form emulsions up to 30 days (Fig. 3C). Therefore, these results showed that the rhamnolipids mixture obtained from strain DN1 could be an effective biosurfactants involving in the biodegradation of hydrophobic compounds by reducing the surface tension of the phase boundary, thus making the substrate more readily available for uptake and metabolism.

\subsection{Structural analysis of biosurfactants}

Rhamnolipids consist of one or two units of rhamnose linked to between one and three fatty acid chains, these chains can be saturated or unsaturated, and their length can vary from $\mathrm{C}_{8}$ to $\mathrm{C}_{16}$. Generally, rhamnolipids are a mixture of different congeners, with the predominant molecules being Rha- $\mathrm{C}_{10}-\mathrm{C}_{10}$ and $\mathrm{Rha}-\mathrm{Rha}-\mathrm{C}_{10}-\mathrm{C}_{10}$. The spectrum of rhamnolipids produced by $P$. aeruginosa is highly dependent on the individual strain, carbon sources, culture conditions and isolation procedures (Müller et al., 2011).

The fatty acid compositions of the purified biosurfactants showed that the most 
abundant fatty acid (around 65\%) was 3-hydroxydecanoic acid $\left(\mathrm{C}_{10}\right), \mathrm{C}_{12}$ and $\mathrm{C}_{8}$ were only next to $\mathrm{C}_{10}$, Other fatty acids such as $\mathrm{C}_{14}$ and $\mathrm{C}_{16}$ were found in smaller amounts. The alditol acetate derivatives of purified fractions indicated exclusively rhamnitol, confirming the presence of rhamnose in the biosurfactants. Figure $4 \mathrm{~A}$ presented the base peak ion intensity chromatograms of the purified rhamnolipids that were produced by strain DN1. The profiles of the chromatograms demonstrated presence of a total of 13 components of various rhamnolipids in this strain, which included the dirhamnolipid congeners containing $\mathrm{C}_{10}, \mathrm{C}_{12}, \mathrm{C}_{14}, \mathrm{C}_{8}-\mathrm{C}_{10}, \mathrm{C}_{10}-\mathrm{C}_{8: 1}, \mathrm{C}_{10}-\mathrm{C}_{10}, \mathrm{C}_{10}-\mathrm{C}_{12}$ as well as the monorhamnolipid congeners containing $\mathrm{C}_{12: 2}, \mathrm{C}_{12}, \mathrm{C}_{8}-\mathrm{C}_{8}, \mathrm{C}_{10: 1}-\mathrm{C}_{8}$, $\mathrm{C}_{14}-\mathrm{C}_{16}, \mathrm{C}_{16}-\mathrm{C}_{16}$ moieties. The proportions of various rhamnolipids listed in Table 1 were obtained from relative intensities of their corresponding parent ions. Further ESI-MS analysis of those parent ions gave fragment ions and shown in Fig. 4B, 4C, and 4D The parent ions at 651.5669 was dominant and could be assigned to dirhamnolipid [Rha-Rha- $\left.\mathrm{C}_{10}-\mathrm{C}_{10}{ }^{+} \mathrm{H}\right]^{+}$, which was consistent with previous reports for P.aeruginosa SWP4, LBI and NY3 (Deepika et al., 2015; Lan et al., 2015; Titschke et al., 2005). The parent ions at $\mathrm{m} / \mathrm{z} 481.3649,509.3302 .4,679.5126$ and 449.3254 were less abundant and could be assigned to $\left[\mathrm{Rha}-\mathrm{C}_{8}-\mathrm{C}_{8}+\mathrm{H}\right]^{+}$, $\left[\mathrm{Rha}-\mathrm{Rha}-\mathrm{C}_{10}+\mathrm{H}\right]^{+}$, $\left[\text { Rha }- \text { Rha }-\mathrm{C}_{12}+\mathrm{H}\right]^{+}$, and $\left[\mathrm{Rha}-\mathrm{Rha}-\mathrm{C}_{10}-\mathrm{C}_{12}+\mathrm{H}\right]^{+}$, respectively. The results shown here supported that the chemical composition of rhamnolipid congeners diverges by the presence of unsaturated bonds, the length of the carbon chain and the size of the hydrophilic head-group owing to multiple factor, like individual strain, carbon source, culture conditions and isolation procedures, and emphasized the important specific 
strain and carbon source (Nitschke et al., 2009; Nie et al., 2010). Strain DN1 had capability to produce many more minor or trace components of rhamnolipids. Therefore, a total of 13 components of rhamnolipid congeners produced by strain DN1, which represented 25 different metal ion $\left(\mathrm{H}^{+}\right.$and/or $\left.\mathrm{Na}^{+}\right)$adducts, were detected by HPLC/ESI-MS, many of which were present in only minute concentrations.

\subsection{Biodegradation of crude oil by strain DN1}

The growth of strain DN1 and the degradation of crude oil were shown in Fig. 5. At the time of inoculation, CFU of DN1 cell feed was about $5.9-6.1 \times 10^{6} / \mathrm{ml}$. The growth of strain DN1 showed the characteristic of a growth curve with an initial exponential growth, followed by a stationary phase from day 8-12. Although, the amount degraded by strain DN1 was relatively small in the first two days, there was sharp increase in the consumption of crude oil from day 3. By the end of 8 days, a totally $59 \%$ of crude oil was removed and the strain DN1 continued to degrade them up to 12 days. After 14 days of incubation, DN1 metabolized crude oil by $90.52 \%$.

Thus, strain DN1 was confirmed that it had capability of producing highest yields of structurally diverse rhamnolipids but, it was able to degrade crude oil efficiently. The maximum removal rates were coincidently occurred by the end of the exponential phase and the start of the stationary phase of bacterial growth, which suggested that rhamnolipids from strain DN1 could increase the water solubility of hydrocarbons, thus making the substrate more readily available for uptake and biodegradation. Rhamnolipids can also remove LPS from cell surface, which could enhance the direct 
contact between cells and substrate (Sharma et al., 2009; Singh et al., 2009). These factors cause an increase in the cell hydrophobicity and consequently enhance the direct contact between cells and the substrate. Further works about degradation mechanism will focus on the hydrophilic or hydrophobic characteristic of cell surface, hydroxylase enzymes and gene cluster of crude oil or HMW-PAHs degradation.

\section{ACKNOWLEDGMENTS}

We kindly thank Pu Xia for excellent support during HPLC/ESI-MS and GC-MS analysis. This program is supported by the National Science Foundation for Fostering Talents in Basic Research of the National Natural Science Foundation of China (Grant No. J1210063) and the National High Technology Research and Development Program 863: Research of microbial enhanced oil recovery in the field of resources and environment (S2013AA0644) and the National Science Foundation for Young Scientists of China (Grant No. 31000069) and Industrializated cultivation project of Shaanxi Education Department (15JF032).

\section{References}

Abalos, A.P.A., Infante, M.R., Casals, M., Carcia, F., Manresa, A.: Physicochemical and antimicrobial properties of new rhamnolipids produced by Pseudomonas aeruginosa AT10 from soybean oil refinery wastes. Langmuir 17, 1367-1371 (2001).

Amani, H., Müller, M. M., Syldatk, C., Hausmann, R. : Production of microbial rhamnolipid by Pseudomonas aeruginosa MM1011 for ex situ enhanced oil 
recovery. Appl Biochem Biotechnol, 170, 1080-1093 (2013).

Bordoloi, N.K., Konwar, B.K.: Microbial surfactant-enhanced mineral oil recovery under laboratory conditions. Colloids Surf. B 63,73-82 (2008).

Chayabutra, C., Wu, J., Ju, L.: Rhamnolipid production by Pseudomonas aeruginosa under denitrification: effects of limiting nutrients and carbon substrates. Biotechnol. Bioeng. 72, 25 - 33 (2001).

Cooper, D.G., Goldenberg, B.G.: Surface-active agents from two Bacillus species. Appl. Environ. Microbiol. 53, 224 - 229 (1987).

Deepika, K. V., Kalam, S., Sridhar, P. R., Podile, A. R., Bramhachari, P. V. Optimization of rhamnolipid biosurfactant production by mangrove sediment bacterium Pseudomonas aeruginosa KVD-HR42 using response surface methodology. Biocatalysis and Agricultural Biotechnology, 5, 38-47 (2016).

Deepika, K. V., Sridhar, P. R., \& Bramhachari, P. V. Characterization and antifungal properties of rhamnolipids produced by mangrove sediment bacterium Pseudomonas aeruginosa strain KVD-HM52. Biocatalysis and Agricultural Biotechnology, 4(4), 608-615 (2015).

Edinger, R. C. , Migneault, P .C., Nolte, F. S. : Supplementary rapid biochemical test panel for the API 20E bacterial identification system. J Clin Microbiol. 22(6): 1063-1065 (1985).

Geys, R., Soetaert, W., and Bogaert IV.: Biotechnological opportunities in biosurfactant production. Curr. Opin. Biotechnol. 30, 66-72 (2014).

Giani, C., Wullbrandt, D., Rothert, R., Meiwes, J.: Pseudomonas aeruginosa and 
its Use in a Process for the Biotechnological Preparation of 1-rhamnose. US005658793A. Hoechst Aktiengesellschaft, Frankfurt am Main, Germany. (1997).

Gudina, E.J., Pereira, J.F.B., Rodrigues, L.R., Coutinho, J.A.P., Teixeira, J.A.: Isolation and study of microorganisms from oil samples for application in microbial enhanced oil recovery. Int. Biodeterior. Biodegrad. 68, 56-64 (2012).

Henkel, M., Müller, M.M., Kügler, J.H., Lovaglio, R.B., Contiero, J., Syldatk, C., Hausmann, R.: Rhamnolipids as biosurfactants from renewable resources: Concepts for next-generation rhamnolipid production. Process Biochem. 47, 1207-1219(2012).

Kanaly, R.A., Harayama, S.: Advances in the field of high-molecular-weight polycyclic aromatic hydrocarbon biodegradation by bacteria. Microbial. Biotechnol. 3, 136-164 (2010).

Kumar, S., Nei, M., Dudley, J., Tamura, M.: MEGA: a biologist-centric software for evolutionary analysis of DNA and protein sequences. Brief Bioinform. 9, 299 $306(2008)$.

Lan, G.H., Fan, Q., Liu, Y.Q., Chen, C., Li, G.X., Liu, Y.: Rhamnolipid production from waste cooking oil using Pseudomonas SWP4. Biochem. Eng. J. 101, 44-54 (2015).

Lee, Y.K., Kwon, K.K., Cho, K.H., Kim, H.W., Park, J.H., Lee, H.K.: Culture and identification of bacteria from marine biofilms. J. Microbiol. 41, 183 - 188 (2003).

Liang, H.H., Li, L.L., Dong, Z.L., Surette, M.G., Duan, K.M.: The YebC family 
protein PA0964 negatively regulates the Pseudomonas aeruginosa quinolone signal system and pyocyanin production. J. Bacteriol. 190, 6217-6227 (2008).

Mao, X.H., Jiang, R., Xiao, W., Yu, J.G.: Use of surfactants for the remediation of contaminated soils: A review. J. Hazard. Mater. 285, 419-35 (2015).

Mata-Sandoval, J.C., Karns, J., Torrents, A.: Effect of nutritional and environmental conditions on the production and composition of rhamnolipids by Pseudomonas aeruginosa UG2. Microbiol Res. 155, 249-256 (2001).

Müller, M.M., Hörmann, B., Kuge,l M., Syldatk, C., Hausmann, R.: Evaluation of rhamnolipid production capacity of Pseudomonas aeruginosa PAO1 in comparison to the rhamnolipid over-producer strains DSM 7108 and DSM 2874. Appl. Microbiol. Biotechnol. 89, 585 - 592 (2011).

Müller, M.M., Kügler, J.H., Henkel, M., Gerlitzki, M., Hörmann, B., Pöhnlein, M., Syldatk, C., Hausmann, R.: Rhamnolipids-Next generation surfactant. J. biotechnol. 162, 366-80 (2012).

Nie, M.Q., Yin, X.H., Ren, C.Y., Wang, Y., Xu, F., Shen, Q.R.: Novel rhamnolipid biosurfactants produced by a polycyclic aromatic hydrocarbon-degrading bacterium Pseodomonas aeruginosa strain NY3. Biotechnol. Advances 28, 635-643 (2010).

Nitschke, M., Costa, S., Contiero, J.: Structure and applications of a rhamnolipid surfactant produced in soybean oil waste. Appl. Biochem. Biotechnol. 160, 2066-2074 (2009).

Onwosi, C.O., Odibo, F.J.: Effects of carbon and nitrogen sources on rhamnolipid biosurfactant production by Pseudomonas nitroreducens isolated from soil. World 
J. Microbiol. Biotechnol. 28, 937-942 (2012).

Patel, J., Borgohain, S., Kuamr, M., Rangarajan, V., Somasundaran, P., Sen, R.: Recent developments in microbial enhanced oil recovery. Renewable and Sustainable Energy Reviews, 52, 1539-1558 (2015).

Prieto, L.M., Michelon, M., Burkert, J.F.M., Kalil, S.J., Burkert, C.A.V.: The production of rhamnolipid by a Pseudomonas aeruginosa strain isolated from a southern coastal zone in Brazil. Chemosphere 71,1781-1785 (2008).

Reis, R.S., Pereira, A.G., Neves, B.C., Freire, D.M.G.: Gene regulation of rhamnolipid production in Pseudomonas aeruginosa - a review. Bioresour. Technol. 102, 6377-6384 (2011).

Rulkens, W.H., Bruning, H.: Cleanup technologies for dredged fine sediments: review and future challenges. In: Olfenbuttel, R.F., White, P.J. (Eds.), Remediation of Contaminated Sediments: Finding Achievable Risk Reduction Solutions. Battle Press, Columbus, Ohio, USA, pp. C6-01 (2005).

Schenk, T., Schuphan, I., Schmidt, B.: High-performance liquid chromatographic determination of the rhamnolipids produced by Pseudomonas aeruginosa. J. Chromatogr. A 693, 7 - 13 (1995).

Sharma, S., Singh, P., Raj, M., Chadha, B.S., Saini, H.S.: Aqueous phase partitioning of hexachlorocyclohexane $(\mathrm{HCH})$ isomers by biosurfactant produced by Pseudomonas aeruginosa WH-2. J. Hazard Mater. 171, 1178 - 1182 (2009).

Sheppard, J.D., Mulligan, C.N.: The production of surfactin by Bacillus subtilis grown on peat hydrolysate. Appl. Microbiol. Biotechnol. 27, 110-116 (1987). 
Silva, I. S., Santos, E. C., De Menezes, C. R., De Faria, A. F., Franciscon, E., Grossman, M., Durrant, L. R.: Bioremediation of a polyaromatic hydrocarbon contaminated soil by native soil microbiota and bioaugmentation with isolated microbial consortia. Bioresour. Technol. 100, 4669-4675 (2009).

Singh, P.B., Sharma, S., Saini, H.S., Chadha, B.S.: Biosurfactant production by Pseudomonas sp.and its role in aqueous phase partitioning and biodegradation of chlorpyrifos. Lett. Appl. Microbiol. 49, 378 - 383 (2009).

Titschke, M., Costa, S.G., Haddad, R., Goncalves, L.A., Eberlin, M.N., Contiero, J.: Oil wastes as unconventional substrates for rhamnolipid biosurfactant production by Pseudomonas aeruginosa LBI. Biotechnol. Prog. 21, 1562 - 1566 (2005).

Thompson, J.D., Gibson, T.J., Plewniak, F., Jeanmougin, F., Higgins, D.G.: The Clustal X windows interface: flexible strategies for multiple sequence alignment aided by quality analysis tools. Nucleic Acids Res. 24, 4876 - 4882 (1994).

Wu, J.Y., Yeh, K.L., Lu, W.B., Lin, C.L., Chang, J.S.: Rhamnolipid production with indigenous Pseudomonas aeruginosa EM1 isolated from oil-contaminated site. Bioresour Technol. 99, 1157-1164 (2008). 


\section{Figure legends}

Fig.1. Phylogenetic relationship between strain DN1 and species in the Pseudomonas based on the 16S rRNA gene sequences, constructed by Neighbor-Joining algorithim

Fig. 2. Expression profiles and corresponding growth curves for strain DN1-lux with different changes of substrates, made under basal BPLM medium. (A) Carbon sources such as soybean oil, rapeseed oil, palm oil, and so on; (B) Nitrogen sources such as ammonium nitrate, urea, ammonium chloride and sodium nitrate; $(\mathrm{C}) \mathrm{C} / \mathrm{N}$ ratio from 10 to 100 .

Fig.3 Rhamnolipid production kinetics, obtained by cultivation of strain DN1 in the optimum culture medium at $30^{\circ} \mathrm{C}$. (A) Growth and rhamnolipid concentration profiles; (B) Surface tension versus dilution ratio between water and the cell-free broth; (C) The ability of rhamnolipids to emulsify different hydrocarbons.

Fig.4 HPLC chromatogram and ESI-MS profiles of partial rhamnolipids produced by Pseudomonas aeruginosa strain DN1. (A) Partial HPLC profiles; (B) Base peak ion intensity spectra at some $\mathrm{m} / z$ via ESI-MS of Rha-Rha- $\mathrm{C}_{10}-\mathrm{C}_{10},(\mathrm{C}) \mathrm{Rha}-\mathrm{Rha}-\mathrm{C}_{8}-\mathrm{C}_{10}$ and (D) Rha-Rha- $\mathrm{C}_{10}-\mathrm{C}_{8: 1}$ on a Micromass Q-TOF mass spectrometer (Waters) coupled to a Dionex HPLC system with use of a Gemini C18 column $(2 \times 50 \mathrm{~mm}, 10 \mathrm{~nm}, 5$ $\mu \mathrm{m}$, Phenomenex).

Fig.5. Time course of pollutant degradation by the DN1 strain when it was inoculated in $200 \mathrm{~mL}$ of the optimized medium composition of BPLM with crude oil as the sole carbon source. 


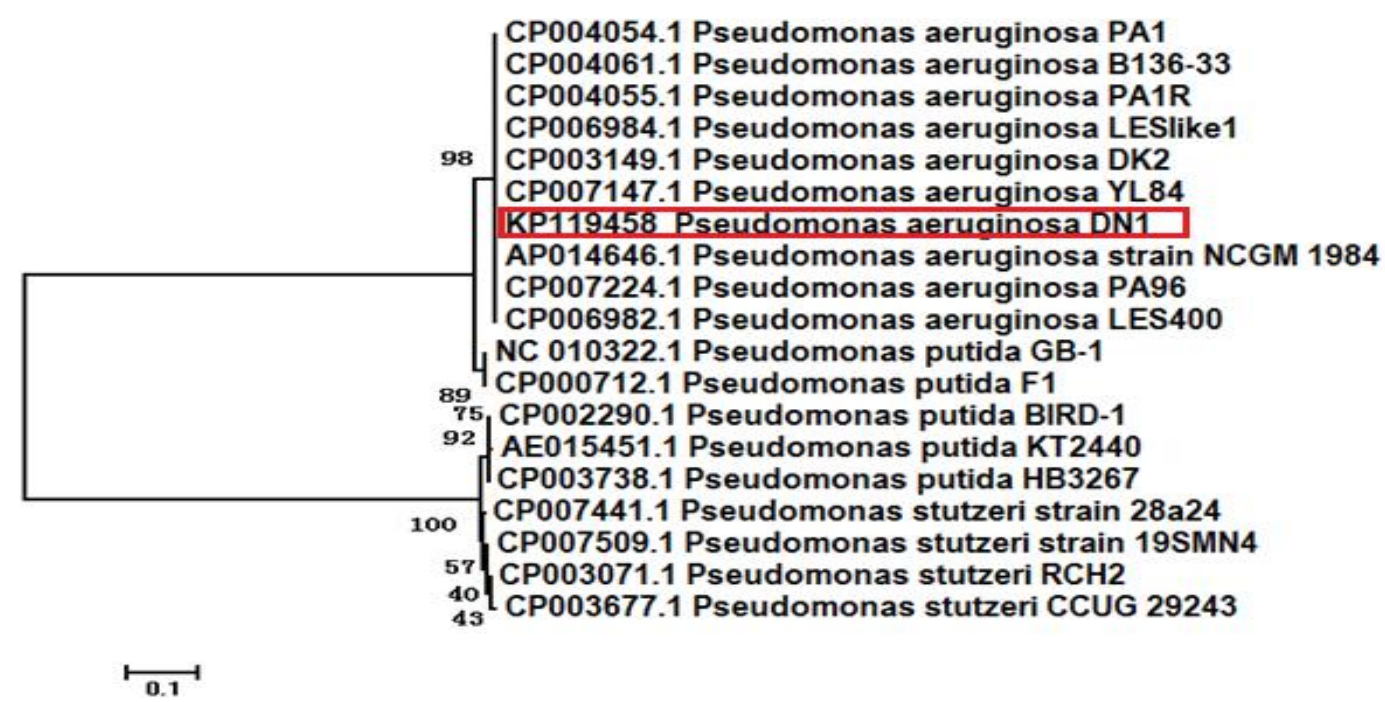

Fig. 1 Phylogenetic relationship between strain DN1 and species in the Pseudomonas based on the 16S rRNA gene sequences, constructed by Neighbor-Joining algorithim 

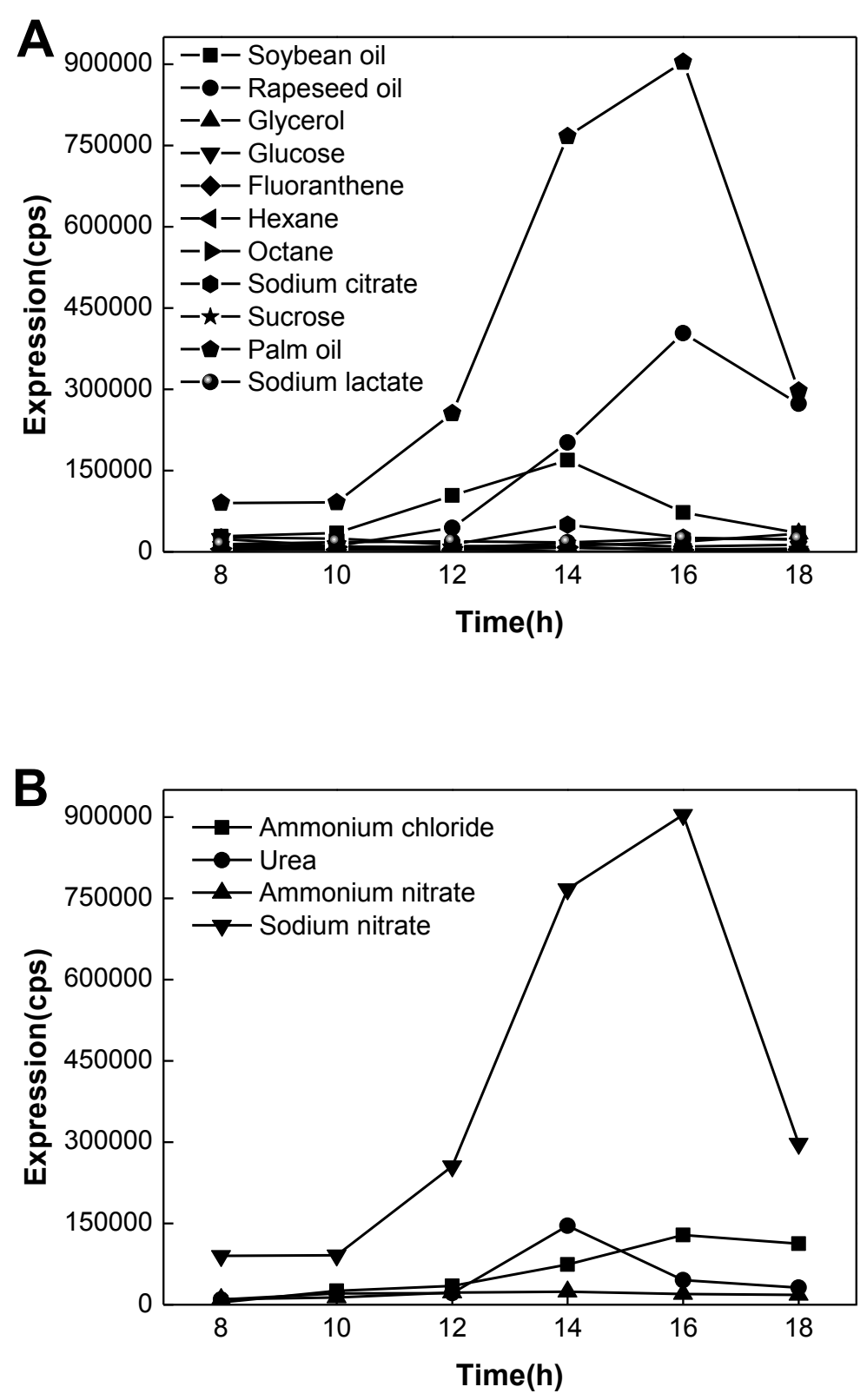


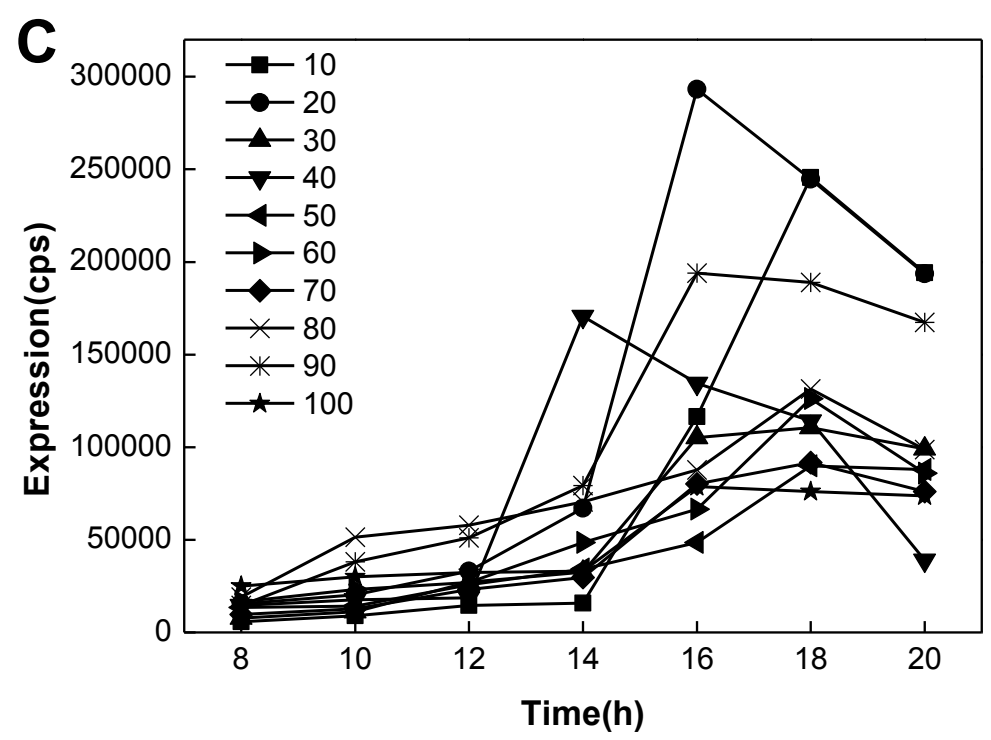

Fig.2 Expression profiles and corresponding growth curves for strain DN1-lux with different changes of substrates, made under basal BPLM medium. (A) Carbon sources such as soybean oil, rapeseed oil, palm oil, and so on; (B) Nitrogen sources such as ammonium nitrate, urea, ammonium chloride and sodium nitrate; $(\mathrm{C}) \mathrm{C} / \mathrm{N}$ ratio from 10 to 100 .

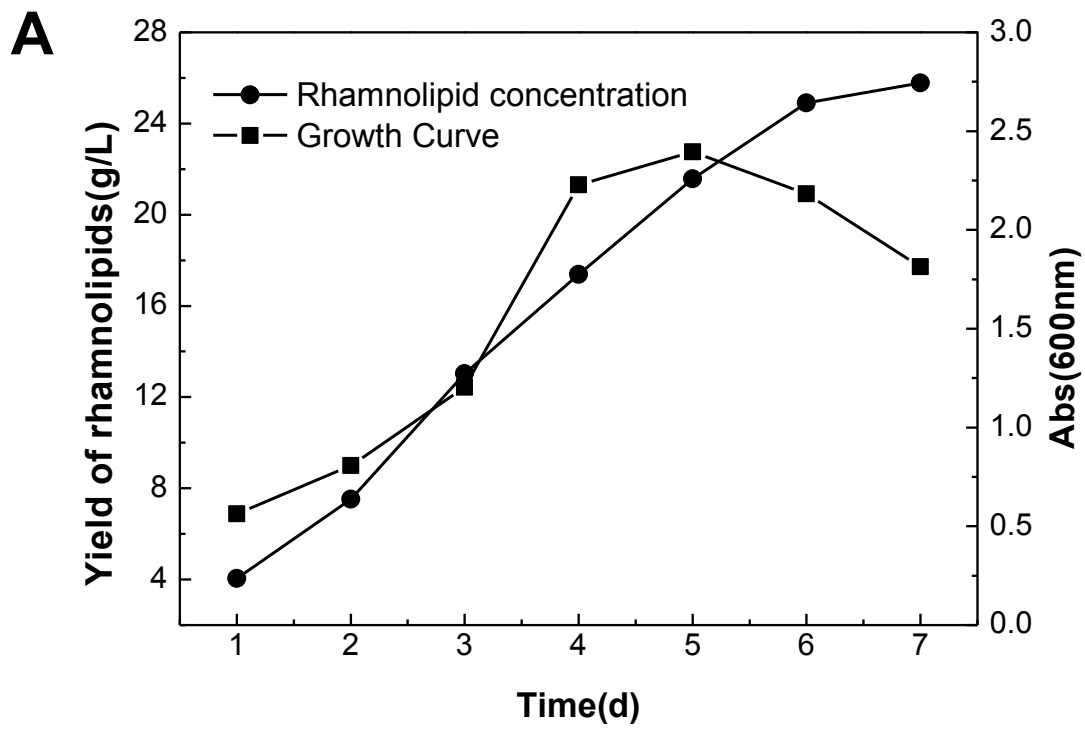



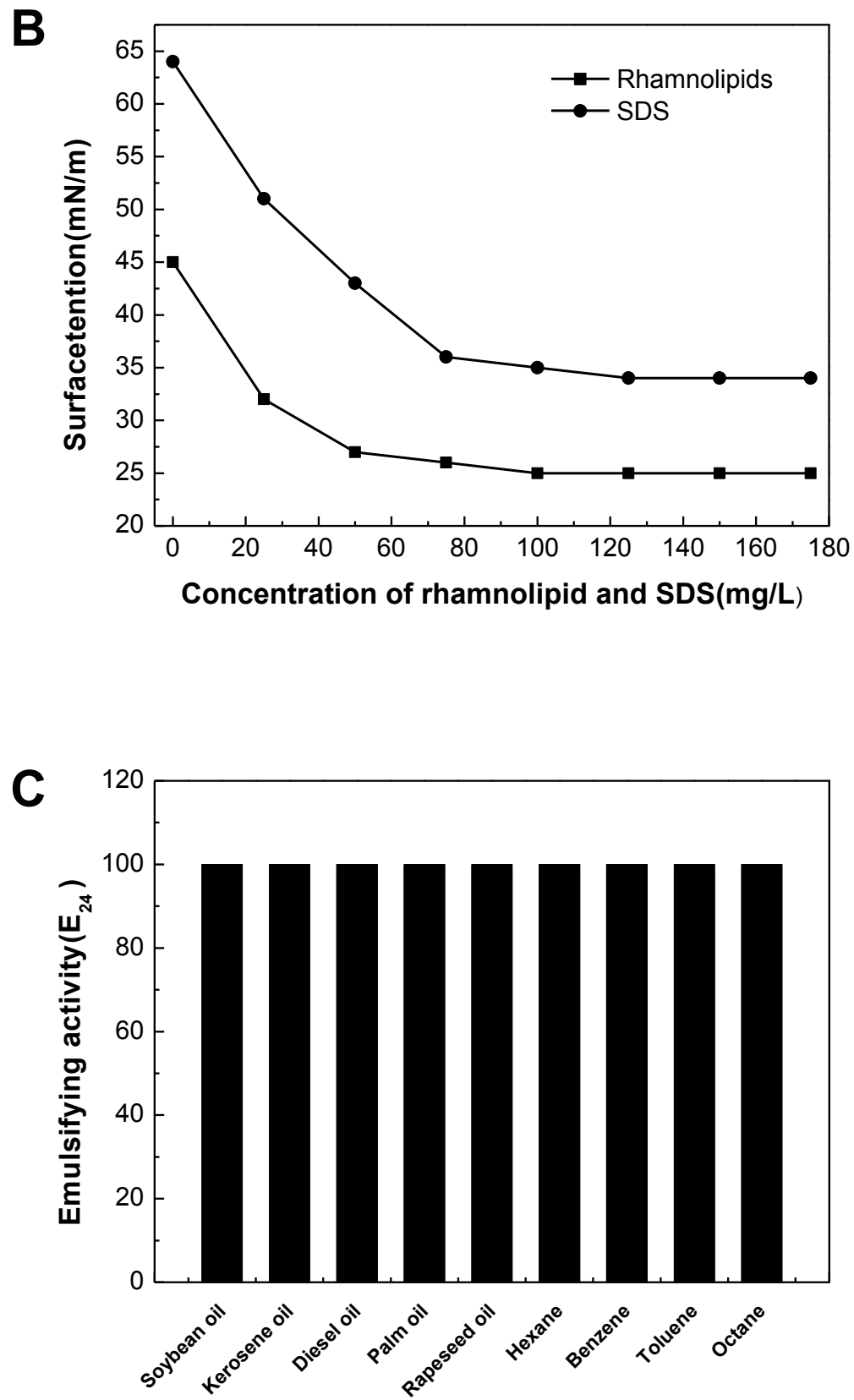

Fig.3 Rhamnolipid production kinetics, obtained by cultivation of strain DN1 in the optimum culture medium at $30^{\circ} \mathrm{C}$. (A) Growth and rhamnolipid concentration profiles; (B) Surface tension versus dilution ratio between water and the cell-free broth; (C) The ability of rhamnolipids to emulsify different hydrocarbons. 

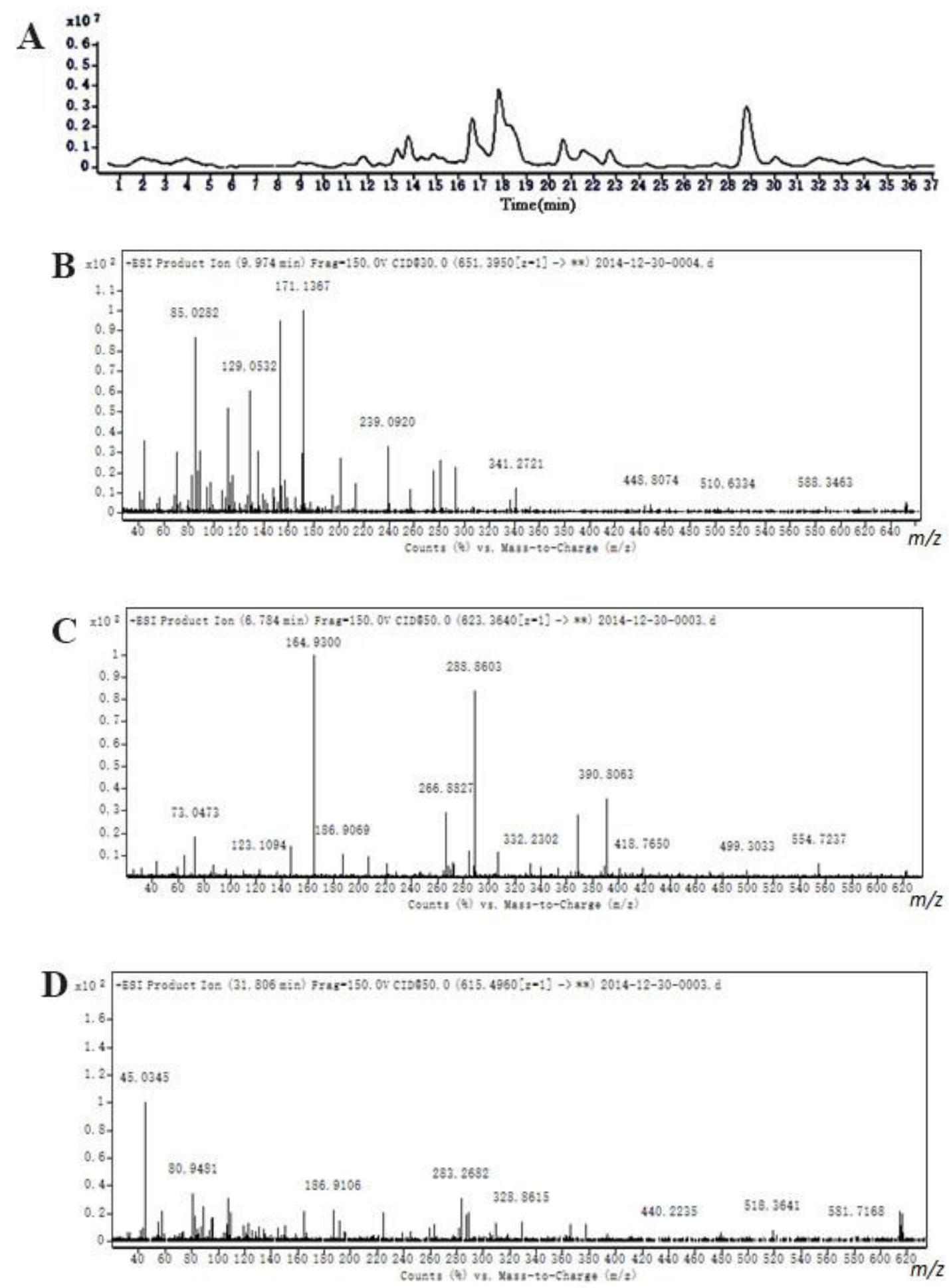

Fig.4 HPLC chromatogram and ESI-MS profiles of partial rhamnolipids produced by

Pseudomonas aeruginosa strain DN1. (A) Partial HPLC profiles; (B) Base peak ion intensity spectra at some $m / z$ via ESI-MS of Rha-Rha- $\mathrm{C}_{10}-\mathrm{C}_{10}$, (C)Rha-Rha- $\mathrm{C}_{8}-\mathrm{C}_{10}$ and (D) Rha-Rha- $\mathrm{C}_{10}-\mathrm{C}_{8: 1}$ on a Micromass Q-TOF mass 
spectrometer (Waters) coupled to a Dionex HPLC system with use of a Gemini C18 column $(2 \times 50 \mathrm{~mm}, 10 \mathrm{~nm}, 5 \mu \mathrm{m}$, Phenomenex $)$.

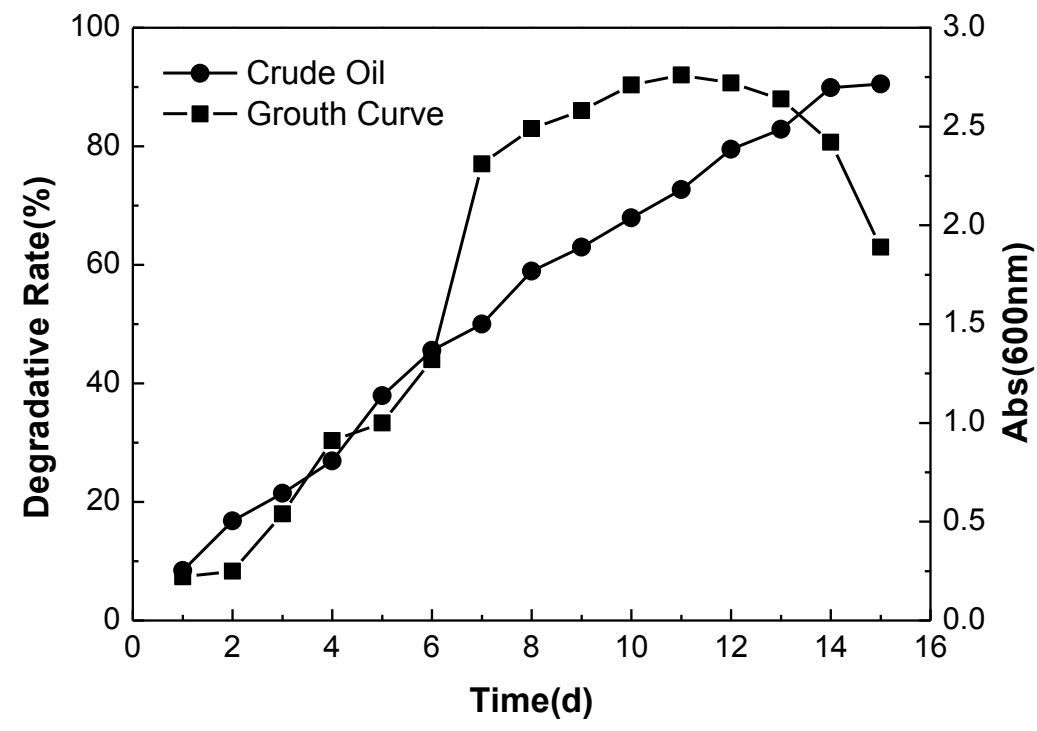

Fig.5 Time course of pollutant degradation by the DN1 strain when it was inoculated in $200 \mathrm{~mL}$ of the optimized medium composition of BPLM with crude oil as the sole carbon source. 
Table 1 Chemical structure of different identified rhamnolipid observed in strain DN1

\begin{tabular}{|c|c|c|c|c|c|c|}
\hline Symbol & $\begin{array}{l}\text { Molecular } \\
\text { formula }\end{array}$ & $\begin{array}{l}\text { Mass Unit } \\
{[\mathrm{M}]}\end{array}$ & {$[\mathrm{M}+\mathrm{H}]^{+} \mathrm{Obsd}$} & $\begin{array}{c}{[\mathrm{M}+\mathrm{Na}]^{+}} \\
\text {Obsd }\end{array}$ & $\begin{array}{l}\text { Retention time } \\
\text { (min) }\end{array}$ & Main mass fragments $(\mathrm{m} / \mathrm{z})$ \\
\hline \multicolumn{7}{|l|}{ Monorhamnolipids } \\
\hline Rha- $\mathrm{C}_{8}-\mathrm{C}_{8}$ & $\mathrm{C}_{22} \mathrm{H}_{40} \mathrm{O}_{9}$ & 448.5484 & 449.3254 & - & 10.853 & $143,165,285,307$ \\
\hline Rha- $\mathrm{C}_{12}$ & $\mathrm{C}_{18} \mathrm{H}_{34} \mathrm{O}_{7}$ & 362.4982 & 363.2261 & - & 23.015 & 165,197 \\
\hline Rha- $\mathrm{C}_{10: 1}-\mathrm{C}_{8}$ & $\mathrm{C}_{24} \mathrm{H}_{42} \mathrm{O}_{9}$ & 474.5947 & 475.3456 & - & 13.176 & $143,165,311,333$ \\
\hline \multicolumn{7}{|l|}{ Dirhamnolipids } \\
\hline Rha-Rha- $\mathrm{C}_{10}$ & $\mathrm{C}_{22} \mathrm{H}_{40} \mathrm{O}_{11}$ & 480.3066 & 481.3649 & - & 19.624 & $165,171,311,335$ \\
\hline Rha-Rha- $\mathrm{C}_{12}$ & $\mathrm{C}_{24} \mathrm{H}_{44} \mathrm{O}_{11}$ & 508.3229 & 509.3302 & - & 21.280 & $165,197,311,363$ \\
\hline Rha-Rha- $\mathrm{C}_{14}$ & $\mathrm{C}_{26} \mathrm{H}_{38} \mathrm{O}_{11}$ & 536.5281 & 537.5354 & - & 21.472 & $165,227,311,391$ \\
\hline Rha-Rha- $\mathrm{C}_{10^{-}}-\mathrm{C}_{10}$ & $\mathrm{C}_{32} \mathrm{H}_{58} \mathrm{O}_{13}$ & 650.5596 & 651.5669 & 673.5044 & 13.768 & $147,165,171,311,341,481$ \\
\hline
\end{tabular}

